Article

\title{
Neighbourhood Impacts on Wellbeing: The Role of Housing among Low-Income Tenants
}

\author{
Steve Rolfe ${ }^{1, *}$ and Lisa Garnham ${ }^{2}$ \\ ${ }^{1}$ Faculty of Social Sciences, University of Stirling, Stirling, FK9 5NL, UK; E-Mail: steve.rolfe1@stir.ac.uk \\ ${ }^{2}$ Glasgow Centre for Population Health, Glasgow, G40 2QH, UK; E-Mail: lisa.garnham@glasgow.ac.uk \\ * Corresponding author
}

Submitted: 10 December 2019 | Accepted: 9 March 2020 | Published: 31 July 2020

\begin{abstract}
The existing literature on neighbourhood effects suggests that a number of factors within local areas can have an impact on health, including environmental hazards, social networks and the socio-economic status of the area. However, there is minimal evidence regarding the role of housing organisations in shaping these effects. This article sets out the findings from a three-year longitudinal, mixed methods study of tenants of three housing organisations operating in the social and private rented sectors, examining different aspects of neighbourhood experience and their relationship to health and wellbeing outcomes. The findings demonstrate impacts of the immediate environment in terms of close neighbours, the wider neighbourhood environment, and social support networks, which are heavily influenced by tenant characteristics, previous experience and expectations. The services provided by housing organisations, themselves shaped by regulation and market factors, are also important. The findings will have relevance for tenants, housing providers, public health professionals and policy makers.
\end{abstract}

\section{Keywords}

home; housing; low-income tenants; neighbourhoods; social capital; wellbeing

\section{Issue}

This article is part of the issue "Home, Housing and Communities: Foundations for Inclusive Society" edited by Isobel Anderson (University of Stirling, UK), Vikki McCall (University of Stirling, UK) and Joe Finnerty (University College Cork, Ireland).

(C) 2020 by the authors; licensee Cogitatio (Lisbon, Portugal). This article is licensed under a Creative Commons Attribution 4.0 International License (CC BY).

\section{Introduction}

The notion that location is everything in relation to housing choice has become a cliché, particularly in relation to middle-class owner-occupiers (Karsten, 2007). However, for low-income households in either social housing or the private rented sector, locational choice is considerably constrained by both allocation procedures and cost. In this context, it is particularly important to understand the potential effects of location on tenants' health and wellbeing since problematic neighbourhood effects may contribute to existing health inequalities. In this article we explore the effects of the neighbourhood on health and wellbeing, drawing on a longitudinal, mixedmethods study of predominantly low-income tenants from three housing organisations operating in west central Scotland, UK. We examine the differential effects of various aspects of neighbourhood quality and local social capital, as well as the ways in which housing organisations can influence such effects across the social and private rented sectors.

\subsection{Neighbourhood Effects on Health and Wellbeing}

The effects of the neighbourhood on health and wellbeing are intertwined in complex ways with the impacts of household socio-economic status. This creates a degree of difficulty, particularly for quantitative studies, in unravelling the differential effects of individual and household poverty from neighbourhood-wide concentrations 
of poor households and the physical and social contexts that neighbourhoods provide. There is nevertheless an extensive literature that sets out to identify the key aspects of the neighbourhood that influence health and wellbeing, some of which attempts to control for or take account of attendant impacts of individual or household deprivation in a variety of ways.

There is strong evidence that there are negative health effects of neighbourhood noise (Braubach, Jacobs, \& Ormandy, 2011; World Health Organization Europe, 2007), environmental hazards (Braubach \& Fairburn, 2010), and crime and violence (Anderson \& Barclay, 2003). While these factors demonstrate a socio-economic gradient, being more prevalent in more deprived neighbourhoods (Braubach \& Fairburn, 2010), there is also evidence that there is a small but significant additional impact of neighbourhood socioeconomic status on health outcomes, independent of such neighbourhood characteristics (Pickett \& Pearl, 2001; Sellström \& Bremberg, 2006). Moreover, some US programmes demonstrate positive health effects from moving low-income families to less disadvantaged areas (Acevedo-Garcia et al., 2004; Gibson et al., 2011).

Alongside this, there is more complex evidence of an association between the social capital available within neighbourhoods and health outcomes (Kawachi, Subramanian, \& Kim, 2008; Vyncke et al., 2013). Social capital can be usefully defined as 'networks together with shared norms, values and understandings that facilitate co-operation within or among groups' (OECD, 2001, p. 41). Social networks are understood to deliver health and wellbeing benefits by providing a sense of belonging, as well as through the "stress-buffering" effects of social support (Cockerham, Hamby, \& Oates, 2017; Kawachi \& Berkman, 2001).

The evidence for a link between neighbourhood social capital and health is reasonably strong (Helliwell \& Putnam, 2004; Lochner, Kawachi, Brennan, \& Buka, 2003). However, there are complications in terms of which aspects of social capital are most likely to be important in shaping health outcomes (Veenstra, 2000), as well as the extent to which social capital may mitigate or exacerbate socio-economic inequalities, partic- ularly where it is unequally distributed between neighbourhoods (Uphoff, Pickett, Cabieses, Small, \& Wright, 2013; Vyncke et al., 2013). Moreover, there are likely to be differential effects of neighbourhood social capital within neighbourhoods, for example the health and wellbeing of women may be more likely to be affected by the presence or absence of local social ties, due to their greater likelihood of having caring responsibilities (Kawachi \& Berkman, 2001).

In considering social capital as a key driver of the impacts of the neighbourhood on health and wellbeing, three conceptual issues and critiques need to be addressed. Firstly, many studies assess the social capital that operates within the neighbourhood to understand its strength and impact on health and wellbeing (Vyncke et al., 2013). However, in reality, the social connections of residents typically extend (well) beyond the neighbourhood's (imaginary) boundaries (Cummins \& Kim, 2015), particularly given that social capital encompasses three distinct types of social connectionbonding, bridging and linking (see Table 1).

Thus, in examining the potential impacts of neighbourhood social capital on health and wellbeing, it is important to recognise that different neighbourhoods may provide different opportunities across these three levels and that they have the potential to impact on health and wellbeing through diverse pathways. These opportunities are likely to intersect with socio-economic deprivation at both the household and neighbourhood level (Subramanian, Lochner, \& Kawachi, 2003).

Secondly, it is important to note that social capital faces critiques both as a concept and as a measurable category. Alongside the different forms of social capital, there are concerns that it encompasses too many different aspects of social networks and interaction in its various definitions to be a useful term (Poder, 2011). Hence, in examining the role of social capital in terms of potential impacts on health and wellbeing, it is important to consider the different aspects, such as trust, friendships and loose networks.

Thirdly, the meanings of "neighbourhood" are highly diverse and the term is often used interchangeably with the much-contested notion of "community."

Table 1. Types of social capital.

\begin{tabular}{|c|c|c|}
\hline Type of social capital & Description & Example \\
\hline Bonding & $\begin{array}{l}\text { The connections between similar people within a } \\
\text { "community," which act as "sociological superglue" } \\
\text { tying people together (Putnam, 2000) }\end{array}$ & Family, friends, neighbours \\
\hline Bridging & $\begin{array}{l}\text { The connections between people who are more different } \\
\text { and less closely linked, operating a "sociological WD-40" } \\
\text { lubricating broader social activities (Putnam, 2000) }\end{array}$ & $\begin{array}{l}\text { Work colleagues, people living in } \\
\text { different neighbourhoods or } \\
\text { forming part of other communities }\end{array}$ \\
\hline Linking & $\begin{array}{l}\text { The relationships between people and those in a position } \\
\text { of power, particularly relationships between service users } \\
\text { and service providers (Szreter \& Woolcock, 2004) }\end{array}$ & Politicians, service providers \\
\hline
\end{tabular}


As Cummins and Kim (2015) have argued, in order to be clear about the role of neighbourhood and community in people's lives, we need to consider the scale at which people themselves understand and experience these constructs, including the scales at which they create and maintain social connections. As such, an examination of the health and wellbeing impacts of both physical and social aspects of the neighbourhood necessitates a careful consideration of the processes involved and the potential for differential impacts within geographicallydefined areas. Understanding the potential role of housing organisations in relation to such neighbourhood effects is important, given their key role in placing and supporting tenants, and especially low-income tenants, within particular neighbourhoods. This requires an exploration of procedures and practices around housing allocation, housing service, area regeneration and tenancy support. Whilst the existing evidence in these areas is somewhat equivocal in terms of health and wellbeing impacts (e.g., Flores et al., 2018; Thomson, Thomas, Sellstrom, \& Petticrew, 2013), a more differentiated analysis may help to identify which tenants benefit from different forms of housing provision and support in relation to the neighbourhood. This article attempts to do just this, utilising mixed methods data to identify organisational practices and their effects, and examining the causal processes involved.

\section{Context for the Study}

The study followed new tenants from three housing organisations operating in west central Scotland, over the first year of their tenancy. The organisations were selected to enable an exploration of diverse approaches to tenant support across the social and private rented sectors. All three organisations focus on providing housing to low-income and vulnerable households, but have different opportunities and approaches in terms of neighbourhood aspects, as outlined in Table 2 .

West central Scotland encompasses the city of Glasgow and its surrounding suburbs, as well as a num- ber of semi-rural towns and their surrounding countryside. Whilst there is considerable variation across the region, the area as a whole is significantly more deprived than the rest of Scotland or the UK. For example, during the study period, the proportion of Glasgow's population claiming out of work benefits was $16 \%$, against a Scottish level of $11 \%$, whilst $21 \%$ of Glasgow's population were living in income deprivation, against a Scottish level of $12 \%$ (Glasgow Centre for Population Health, 2020). In terms of housing, both Glasgow City and its surrounding local authorities have historically held relatively high proportions of social housing (in a UK context), reaching a peak of around two-thirds of all housing stock in the early 1980s. This proportion has reduced significantly in the last four decades (to around 30\%), whilst the private rented sector has grown substantially since the turn of the century, to nearly $20 \%$ of households. The housing locations available to tenants of the three organisations involved in this study reflect the extent to which social housing and lowcost private rented properties are inevitably in the more deprived neighbourhoods of a generally deprived region. As a result, more than $80 \%$ lived in the most deprived quintile of the Scottish Index of Multiple Deprivation, spread across locations within the region.

\section{Methodology}

All new tenants were invited to participate in the study, being given initial information by housing organisation staff prior to a more detailed conversation and opt-in consent process with the research team. Participation was voluntary, with around $50 \%$ of new tenants agreeing to take part in the study. Participants were interviewed at three time points over the first year of their tenancy, as shown in Table 3. Semi-structured interviews collected a mix of quantitative and qualitative data, covering aspects of the housing experience, neighbourhood and social support, as well as health and wellbeing, finances and demographics.

The drop-out rates between the waves are largely due to two factors. At Wave 1, data was collected

Table 2. Participant organisations.

\begin{tabular}{ll}
\hline Organisation & Description \\
\hline Community-based Housing & Social housing provider, with around 5500 properties in a small area of a large city. \\
Association & Operates points-based allocation process, where greater housing need results in more \\
& points. Undertakes some environmental/regeneration work in areas around its properties. \\
& Delivers a range of community development activities through a subsidiary.
\end{tabular}

Letting Agency

Social enterprise letting agency, managing around 250 properties for the private rented sector landlords and owning a further 200, purchased and refurbished with social investment finance. Properties are dispersed across west central Scotland. Provides intensive tenancy support service to vulnerable tenants.

Rent Deposit Schemes Voluntary sector organisation running two rent deposit schemes, facilitating access to the private rented sector for around 100 households at risk of homelessness per year, through provision of a deposit guarantee. Provides support to tenants for first year of tenancy. Properties are dispersed across two local authority areas in west central Scotland. 
Table 3. Data collection.

\begin{tabular}{lllr}
\hline Wave & Time point & Focus & $\mathrm{N}$ \\
\hline 1 & Start of tenancy & Previous housing situation and baseline health and wellbeing & 121 \\
2 & $2-4$ months into tenancy & New housing situation and short-term impacts on health and wellbeing & 75 \\
3 & $9-12$ months into tenancy & Established housing situation and long-term impacts on health and wellbeing & 45 \\
\hline
\end{tabular}

through a short telephone interview (around $15 \mathrm{~min}$ utes), whereas Waves 2 and 3 involved more onerous face-to-face interviews in the tenants' home of around 30-60 minutes in length. The attrition at Wave 3 was exacerbated by the timescale of the project-some Wave 3 interviews could not be scheduled before data collection had to be completed. These patterns were relatively consistent across the three organisations and the number of tenants moving on or losing their tenancy was very small $(<5 \%)$.

The outcome variables measuring health and wellbeing were the World Health Organization's 5-point wellbeing scale (WHO5) and a self-report question regarding change in overall health and wellbeing. We opted for these measures because of the practical difficulties of accessing clinical health data and the low likelihood of significant changes in such data within a year. Whilst there are inevitably concerns about the objective validity of any self-rated measure, there is an established evidence base which suggests that self-rated health and self-rated change in health are reliable predictors of morbidity and mortality (Gunasekara, Carter, \& Blakely, 2012; Idler \& Benyamini, 1997). Moreover, there is also robust evidence to show that subjective wellbeing as measured by WHO5 is a reliable predictor of wider health outcomes, as well as being an important measure in itself (Steptoe, Deaton, \& Stone, 2015; Topp, Ostergaard, Sondergaard, \& Bech, 2015).

The independent variables were a 4-point selfrating question on neighbourhood quality and a set of four Likert-style statements related to social support drawn from national surveys (Understanding Society and Scottish Household Survey). These social support statements were converted into a single index on the basis of substantial consistency (Cronbach's Alpha from 0.77 to 0.86 across the three waves), although analysis was also conducted on the constituent variables to address concerns regarding the blanket nature of social capital as a concept. More detail on the variables is included in the Supplementary File.

The quantitative data was analysed using bivariate tests in SPSS, to identify possible connections between aspects of neighbourhood and social support, and health and wellbeing outcomes. These relationships were then further explored through Nvivo using thematic qualitative analysis (Braun \& Clarke, 2006) of the qualitative data to examine the processes involved, combined with framework analysis (Ritchie \& Spencer, 1994) to connect the quantitative and qualitative analysis in order to examine any differential patterns between groups of tenants.

\section{Findings}

Analysis of the quantitative data indicated connections between tenants' perceptions and experiences of the local neighbourhood, and their health and wellbeing. Tables 4 and 5 summarise the results of tests carried out (using Spearman's Rho for non-parametric data) on the data from Wave 2, when participants had been in their new tenancies for 2-4 months (the tests were also carried out on Wave 3 data, but the much smaller sample size ( $N=45$ ) inevitably produced weaker correlationstesting on this smaller cohort at both Waves produced no significant results at either Wave. In order to avoid providing a false impression of reducing effect over time, the Wave 3 data is not presented here). The first table shows the correlations at 2-4 months, whilst the second table shows the change that tenants experienced from their previous housing situation to 2-4 months into their new tenancy.

The significant positive correlations in Table 4 suggest there is a strong relationship between tenants' perceptions of neighbourhood quality, as well as their local social support networks, and their wellbeing outcomes. Thus, individuals who rated their new neighbourhood highly, or exhibited a strong sense of social support in their new neighbourhood were significantly more likely to have higher wellbeing than those tenants with lower social support scores. The significant correlations in Table 5 suggest that there is a relationship between a change in neighbourhood quality and social support and a change in health and wellbeing. This means that those individuals who rated the quality of their new neighbourhood as being higher than the area they had moved from,

Table 4. Summary of full sample tests at Wave 2.

\begin{tabular}{llll}
\hline Independent variable & Dependent variable & Rho & Sig. \\
\hline Rating of neighbourhood quality & WHO5 Wellbeing Score & 0.46 & $0.001^{* * *}$ \\
Social support index & & 0.33 & $0.005^{* *}$ \\
\hline
\end{tabular}

Notes: ${ }^{*} \mathrm{p}<0.05,{ }^{* *} \mathrm{p}<0.01,{ }^{* * *} \mathrm{p}<0.001 . \mathrm{N}=75$. 
Table 5. Summary of full sample tests across Waves 1 and 2.

\begin{tabular}{llcc}
\hline Independent variable & Dependent variable & Rho & Sig. \\
\hline Change in rating of neighbourhood quality (Waves 1 to 2) & Self-rated change in health and wellbeing & 0.25 & $0.04^{*}$ \\
Change in social support index (Waves 1 to 2) & & 0.28 & $0.02^{*}$ \\
\hline
\end{tabular}

Notes: ${ }^{*} \mathrm{p}<0.05,{ }^{* *} \mathrm{p}<0.01,{ }^{* * *} \mathrm{p}<0.001 . \mathrm{N}=75$.

or who exhibited an improved sense of social support following their move were significantly more likely to show an improvement in their wellbeing than those tenants whose social support scores had gone down.

The analysis of correlations between the individual social support variables and health and wellbeing outcomes (out using Spearman's Rho for non-parametric data) are provided in Tables 6 and 7.

These tables show that health and wellbeing appear to be particularly related to trust, given the significant correlations both as a static variable and as a measure of change when tenants move between neighbourhoods. In other words, the data suggests that tenants who feel that they can trust their neighbours are likely to have better health and wellbeing than tenants who do not trust their neighbours. There are also significant correlations regarding help and friendships within the neighbourhood. The fact that some elements of social support show significant positive correlations with health and wellbeing, whilst others do not, suggests two things. Firstly, it provides some support for the critiques of social capital as an ill-defined, excessively broad concept, indicating that it may be important to examine different elements of social support and networks to understand potential impacts on health and wellbeing. Secondly, it suggests that examination of the qualitative data may be particularly valuable in elucidating these differences. The remainder of this article explores the possible causal pathways underlying these correlations by drawing on the qualitative data from this study.

\subsection{Neighbourhood Quality}

Participants highlighted the value of local amenities, shops, greenspace and transport links in their home neighbourhood. Notably, perceptions of these physical aspects of the neighbourhood were often couched in relative terms and contrasted with areas participants had lived previously:

I was staying in [another area] before and it's like the middle of nowhere, there's no shops or anything. So, it's like we've got shops five minutes away. Go a walk up there all the time...-I've got the two schools and the weans go into the nursery and it's just a walk along there....So, kind of, close to everything. (Rent Deposit Scheme tenant)

Alongside amenities, aspects relating to crime, antisocial behaviour, noise and personal safety were frequently highlighted by participants as contributing to neighbourhood quality. In particular, feeling safe in the local area was described as reducing worry and stress:

It's a nice area....There's never any trouble round here so that makes for a lot. You know, you can go out at night, go along to the chippy or whatever and you're not going to have to worry about a gang of boys at the top of the street. It's good that way as well. (Rent Deposit Scheme tenant)

Table 6. Summary of tests at Wave 2 for individual social support variables.

\begin{tabular}{llll}
\hline Independent variable & Dependent variable & Rho & Sig. \\
\hline Neighbourhood trust & & 0.32 & $0.007^{* *}$ \\
Neighbourhood conversations & WHO5 Wellbeing Score & 0.16 & 0.2 \\
Neighbourhood help & & 0.29 & $0.02^{*}$ \\
Neighbourhood friendships & 0.21 & 0.07 \\
\hline
\end{tabular}

Notes: ${ }^{*} \mathrm{p}<0.05,{ }^{* *} \mathrm{p}<0.01,{ }^{* * *} \mathrm{p}<0.001 . \mathrm{N}=75$.

Table 7. Summary of tests across Waves 1 and 2 for change in individual social support variables.

\begin{tabular}{llll}
\hline Independent variable & Dependent variable & Rho & Sig. \\
\hline Change in neighbourhood trust & & 0.42 & $0.001^{* *}$ \\
Change in neighbourhood conversations & Self-rated change in health and wellbeing & 0.14 & 0.2 \\
Change in neighbourhood help & & 0.21 & 0.1 \\
Change in neighbourhood friendships & & 0.25 & $0.03^{*}$ \\
\hline
\end{tabular}

Notes: ${ }^{*} p<0.05,{ }^{* *} p<0.01,{ }^{* * *} p<0.001 . \mathrm{N}=75$. 
As with the physical characteristics of the neighbourhood, participants' views of these more social aspects were strongly shaped by their previous experiences, as well as by their expectations, and their personal and household characteristics. Where a new tenancy involved a move to an area with lower perceived levels of crime or anti-social behaviour, participants highlighted the impact this had on their ability to feel at home, which in turn affected their wellbeing and quality of life:

[I'm] 100\% happier. I'm basically not depressed anymore, as soon as I moved out of that flat in [previous area] and moved here it was such a huge change, it was like a weight had been lifted off my shoulders. I don't need to deal with all the idiots and the polis [police] at the weekends...here is just a far cry from how I felt before, I mean, I can actually go outside, I want to go outside and meet people and stuff like that, whereas back there it was 'I don't want to go out, I just want to curl up in a ball, I'm dying for this to all go away.' So now it's just like, aye, bring on life! (Letting Agency tenant)

Further examination of the quantitative data reinforces this relative nature of tenant perspectives and experiences of neighbourhood. Tenants' rating of neighbourhood quality was not, in and of itself, significantly correlated with the neighbourhood-based measures of deprivation, using Scottish Index of Multiple Deprivation deciles $(2 p=0.58)$. However, where tenants relocated to a more or less deprived neighbourhood as part of their move into a new tenancy, this change in area deprivation was significantly correlated with a change in how they felt about the quality of their neighbourhood $(2 p<0.001)$. This suggests that tenants' perceptions of neighbourhood quality are more heavily shaped by any contrasts with their previous neighbourhood than they are by neighbourhood-based measures of deprivation.

Perhaps unsurprisingly, then, familiarity with the neighbourhood was also important in shaping perceptions of its quality. For some, familiarity meant that crime and anti-social behaviour levels were less of a concern because they fitted with expectations of the area:

Well I've lived here on and off since I was 18 so I know the neighbourhood pretty well. It's a quiet place during the week [laugh], but at the weekend with the pub out there it does get a wee bit lively but...I don't sit here in fear, you know, when I hear voices outside or anything like that. (Letting Agency tenant)

Some of those tenants who moved to a new and unfamiliar neighbourhood were pleasantly surprised when the area proved less challenging than its reputation suggested. However, others found the change of environment more difficult to deal with:

It's not bad but it's not a good neighbourhood as well, it's like they have a lot of fights during the night you can see, but that's all over [this city] I think...they are fighting during the nights, like, you can hear them in the street fighting and screaming. (Letting Agency tenant)

Further, tenants' fears and sense of safety were heavily influenced by their sense of vulnerability, both for themselves and their family members. Thus, participants with existing mental health problems or with children were more likely to express reservations about safety, whilst young, male tenants were often dismissive of such risks:

It's not even the neighbours that are noisy. I think it's the walls that are just thin. I can hear what he's watching. Her buzzer goes, I can hear her dog bark....See, as long as I feel safe, I'm alright with noise. But I think 'cause of my [mental health] illnesses and all that, I'm like, oh I don't feel safe in here. (Housing Association tenant, young female)

There was actually a murder a couple of weeks back there, a 24 year old boy got stabbed to death over drugs, but that was way over that way, over by the shops and...It doesn't bother me, I grew up in [city] so I'm used to it all, I mean, nothing up here bothers me...I mean, if I seen somebody my size walking about I'd be like, I'm not going to **** with him, know what I mean. (Rent Deposit Scheme tenant, young male)

Alongside previous experiences, expectations and personal characteristics, tenant's evaluation of the quality of their neighbourhood was made more complex by perceptions of different geographic scales within the local neighbourhood. Some participants felt positively about the very local space around their property, despite concerns about the wider neighbourhood:

It's good yeah, somebody tell my wife [she had] left the key on the door and my neighbour knocked on the door tell the key there, so it's good yeah, very good....But out there it's not that good. Down there so many, you know, young boys, always try to get you some trouble. (Housing Association tenant)

By contrast, other participants were more positive about the wider neighbourhood, whilst expressing concerns about their immediate locality. As such, the salient characteristics of the "neighbourhood," including the ways in which they influenced health and wellbeing, operated at multiple scales and were often not entirely coherent or consistent across those scales. These findings suggest that the relationship between "neighbourhood quality" and health and wellbeing is therefore mediated by participants' previous experiences and expectations of their local neighbourhood, their household characteristics, and the multiple scales at which they inhabit the neighbourhood. 


\subsection{Social Networks and Support}

Turning to the social networks within the neighbourhood, participants described the importance of both proximity to family and friends, and having successful relationships with their immediate neighbours. For many tenants, living near to those family members who could provide positive social contact and support was of significant benefit to their quality of life. It allowed them to draw upon the bonding capital they already had and convert it into practical support:

I've got family round about me anyway if I need them. As I say, my sister's there, my cousin's there, my nephew's round there-they're all intermingled. That's why I love it; it's great here. I should have done this years ago, so I should have. (Housing Association tenant)

Notably, the importance of proximity to family support could also be two-way, with some participants (predominantly women) emphasising the value of being near to vulnerable family members in need of support.

However, opportunities for social support and socialising extended beyond family for most participants and relationships with immediate neighbours were often pivotal. For some, this relationship almost resembled that of a supportive family:

I've got a good relationship with [neighbour] and her husband, yeah, in fact, she checks in on me every other day and the dog checks in on me too so, they're lovely people.....If there was ever an emergency I know who I can go to now and it's nice to know that if anything happened to me I wouldn't lay in here for three weeks. (Rent Deposit Scheme tenant)

Such close neighbourly relationships typically developed not just from the physical proximity of living next door, but because of pre-existing social networks across the local community. Nevertheless, many tenants were able to develop relationships with their neighbours, without holding any pre-existing connections with them, through the first year of their tenancy:

I didn't really know [my neighbours] apart fromhello, how are you doing [when I first moved in]. Now it's, meet them at the shop, meet them at the post office and they all speak more now. You spend maybe five minutes longer than you would have in the past speaking to them, asking what you're up to, what you're doing, you know. (Housing Association tenant)

Importantly, physical places in which neighbours can interact with one another, beyond the immediate vicinity of the building in which they live, appear to be central in helping these relationships, and the bonding capital they provide, to develop.
Nevertheless, there were a significant minority of participants for whom local social relationships were either less important or, indeed, problematic. For some, a substantial social network that extended across the wider city, country or world meant that local social connections were less relevant, so long as they had the resources and mobility to maintain such friendships:

My friends quite like the location of this [property]....because then I'm kind of in between everybody. So, I've got people who stay sort of at [one side of the city], and people that stay like [on other side of the city], and all that. So, it's somewhere in the middle. (Letting Agency tenant)

The importance of these networks, albeit for a minority of tenants, demonstrates the intersection between neighbourhood amenities (e.g., transport) and extralocal social capital, as well as highlighting the potential limitations of analyses that examine social networks only within a geographically-determined neighbourhood.

There were also a number of participants who deliberately avoided building close relationships with their neighbours, because they were concerned about problems that might arise. These concerns were typically based on previous, negative experiences with neighbours:

You just keep your distance over there, I'll say hiya, I'll just be in my own wee world, I don't need you. Well, in the past and growing up, my mum was kinda like really neighbourly, if you want to call her that. But it always backfired on her, so whether it be my mum's young children arguing with the other young children in the neighbourhood or whatever, then...all the adults end up fighting....So from that experience I've learned don't talk to your neighbours, it's not worth it. (Letting Agency tenant)

By contrast, a third group of tenants appeared to want to build a supportive local network in a new and unfamiliar area, but felt themselves excluded by what they perceived as a community closed to incomers, which made it very difficult to establish new social connections:

It's not somewhere to settle unless you're from here probably. 'Cause everybody knows everybody about here....They're all cliquey. If you're not known from here you get stared at. I don't want to be in a place like that. (Housing Association tenant)

Hence, whilst bonding social capital within the neighbourhood is clearly of great importance for some tenants, others may draw on more dispersed networks, be resistant to local connection or see themselves as excluded by a close-knit but unfamiliar community. 


\subsection{Role of Housing Organisations}

There were a range of ways in which the housing organisations examined in this study played a role in enhancing tenants' perceptions and experiences of the neighbourhood, as well as their ability to build bonding capital within it.

In terms of the physical and structural characteristics of the neighbourhood, the community-based Housing Association had the most significant scope to create improvements to the built environment, since it owned a large number of properties within a concentrated area. For example, their tenants highlighted the improvements made to the physical appearance of high-rise blocks and the landscaping around them in improving their enjoyment of the neighbourhood. The ownership of various parcels of land surrounding tenants' homes was a pre-requisite to these extensive environmental improvements, although investments in the common parts of apartment blocks, such as CCTV and concierge staffing, also had significant impacts:

The older ladies...a pair of them have stayed here 50 years, and they love it. I've said, why did you never move, and they said, I'm safe, and...the concierges are really, really good and they feel safe. That's what it comes down to, it's the safety. (Housing Association tenant)

By contrast, the other two housing organisations, whose private rented sector stock was spread across a much wider geography, had much more limited scope to influence neighbourhood quality. However, they were able to offer tenants much greater opportunities to choose the area in which they wanted to live, for example an area they were familiar with or had pre-existing social networks within:

There were other [properties] they offered me as well. They were in the pipeline but the three of them were in [another area] and I didn't really want to live [there] to be honest. It's rough, a bit rough nowadays but that one came up and I thought, [this area], lovely area, nice area. (Rent Deposit Scheme tenant)

They also had greater capacity to help tenants avoid taking up a tenancy in a neighbourhood in which their historical social networks and relationships were potentially problematic. For participants in this study, this flexibility in the private rented sector was not only evident at the start of tenancies, but throughout. Where tenants faced significant difficulties settling into a new neighbourhood, housing organisations were able to support them to move to a new tenancy in a different area:

I got quite depressed and I knocked on [neighbour's] door and I said to him 'I don't think I can hack this, I don't think I can do this for six month' and he said 'listen son, this is not the place to be if you don't have transport, you're really out in the country here'....So I would commend them for the help that they've given me....They didn't have to get me out of [area] after three months...but they have a housing officer who's also a psychologist so I think she could probably tell, you know, 'this guy's struggling a bit, we've got to get him out.' (Letting Agency tenant)

However, the private rented sector landlords have far less capacity to offer choice in neighbourhoods dominated by social housing. Moreover, whilst social housing organisations may be able to help prospective tenants to stay or return to such areas, the combination of pointsbased allocation processes and lifetime tenancies in the sector means that some participants in this study struggled to gain access their ideal neighbourhood:

\section{Researcher: What stops it feeling like home?}

Housing Association Tenant: It's just not the place I wanted to be. I wanted [different area] but you can't get what you want all the time can you, wanted near my sister-in-law and where I was from years ago and where I know most people and I feel comfortable down there.

Beyond creating improvements in the physical environment of the neighbourhood or offering a choice of suitable neighbourhoods, there was one final key way in which housing organisations in this study supported tenants in their new neighbourhoods. For those tenants who lacked bonding capital provided by supportive local social networks, some housing organisations were able to step in and provide social, emotional and practical support, through their own staff:

They've been able to run me out to the hospital to get my dressing changed, take me to the bank....It's general support from them. It's next to none...just a gem of a fella [my housing officer]. Absolute diamond, you know. Anything that he can do to help, he's always asking....That's where I'm getting my help from. (Letting Agency tenant)

These aspects of housing service were particularly important in helping more vulnerable tenants to settle and feel at home in their new tenancy, with long-term implications for health and wellbeing.

\section{Discussion and Conclusion}

At a broad level, this study echoes the findings of existing studies of neighbourhood impacts on health and wellbeing. It supports the role of crime, anti-social behaviour and personal safety issues in affecting tenants' health and wellbeing, particularly in situations where a house move involves a change of area (Acevedo-Garcia 
et al., 2004; Anderson \& Barclay, 2003; Gibson et al., 2011). Moreover, it underlines the importance of social capital, and especially bonding social capital, in providing tenants with a sense of home and belonging, as well as practical and emotional support (Cockerham et al., 2017; Kawachi \& Berkman, 2001).

However, whilst the quantitative data demonstrates a clear connection between neighbourhood quality, social networks and support, and health and wellbeing outcomes, the more detailed quantitative and qualitative analysis demonstrates the complexity and non-linearity of these relationships. The impacts of neighbourhood aspects such as crime and anti-social behaviour are heavily mediated by tenants' expectations, previous experiences and personal/household characteristics. Similarly, within-neighbourhood social capital may provide a relatively poor guide to the social connectedness and, therefore, the health and wellbeing influences of the neighbourhood on its inhabitants. Indeed, the instances of tenants choosing to avoid previously problematic social networks and of being excluded from close-knit communities point towards the so-called "dark side of social capital" (Portes, 1998). Analyses of neighbourhood effects therefore need to do more than control for differences between individuals and households and examine these differences as a route to understanding causality.

Moreover, these findings highlight the ways in which neighbourhood quality and social capital intersect and operate at multiple scales within the neighbourhood, which adds significant complexity to their impacts on health and wellbeing. Again, this has implications in terms of research into neighbourhood effects, emphasising the importance of defining what is meant by neighbourhood in area-based analyses (Cummins \& Kim, 2015), whilst taking cognisance of the varied meanings and geographies experienced by individuals and households. Indeed, there is an extent to which geographicallybounded variables are of limited value in mapping realworld causal processes, raising fundamental questions for exclusively quantitative analysis in this field.

In terms of understanding social capital as a determinant of health and wellbeing, the differences in statistical relationships between the individual social support variables emphasise the need to consider different aspects of social capital, alongside analysis of the broad concept. In this respect, the qualitative evidence around the importance of personal safety chimes with the quantitative evidence regarding neighbourhood trust, suggesting that this may be a particularly important aspect of social capital in influencing wellbeing, at least in the early stages of a new tenancy. Moreover, the role of prior experience and personal characteristics in shaping the impact of neighbourhood and social support points to the importance of examining the relationship between social capital and other forms of capital (Schuller, 2007).

The study also demonstrates the range of ways in which the actions of housing organisations may influence neighbourhood effects. Clearly there are differ- ences across the social and private rented sectors in west central Scotland. Social housing providers operating in concentrated geographic areas may be able to invest in amenities and the built environment, and potentially in supporting healthy social relationships between neighbours, although this latter aspect was not evidenced through our study. Organisations working in the private rented sector have less power to influence such neighbourhood aspects, but may be able to offer prospective tenants significantly greater choice of area, enabling them to have some agency over their neighbourhood of residence, albeit within areas constrained by affordability issues for low-income households. Evidence from tenants in this study therefore provides some support for the shift in Scotland towards choice-based lettings policies, which give tenants greater agency to choose their area of residence. However, the Scottish Government appears to have moved away from its earlier emphasis on maximising choice and there are now questions about whether this policy will come to fruition (Scottish Government, 2011, 2019).

Cutting across both sectors, this study highlights the ways in which housing services can operate to mitigate neighbourhood stressors by responding quickly to problems and even, in some instances, to fill gaps in support networks. Arguably this highlights the particular value of linking social capital (Szreter \& Woolcock, 2004) for lowincome and vulnerable tenants, in the form of their relationships with housing staff. In neighbourhoods where some individuals may struggle to draw on bonding social capital and where the environment causes stress, the opportunity to elicit support from housing services may have significant health and wellbeing benefits. Moreover, in the context of findings showing the substantial individual variability in neighbourhood effects, housing staff may be particularly well placed to understand both the neighbourhood context and the specific needs of vulnerable tenants.

To conclude, this research suggests that many different aspects of the neighbourhood play an important role in shaping health and wellbeing, from the practical to the social. These impacts vary substantially from tenant to tenant, reflecting their needs, previous experiences, expectations and current resources. Crucially, this study has demonstrated that this variation exists across lowincome tenants, who are not a homogeneous group, but individuals who use and benefit from their neighbourhoods differently. Being able to exercise some choice of the location of the home appears to be a critical foundation to ensuring that the neighbourhood has the potential to meet tenants' diverse needs. Finally, where housing organisations recognise these differences between tenants, they can play a valuable role in enabling tenants to get the most benefit from their neighbourhood, including the amenities and social opportunities it has to offer. 


\subsection{Limitations and Future Research}

Whilst this study was able to follow participants for the first year of their tenancy, it would clearly be of value to undertake a longer study, since health and wellbeing impacts may develop, fade or change over time as tenants become more established in their neighbourhoods. Such a study could also incorporate more "objective" measures of health, such as use of health services, since such changes may be visible over a longer period. It would also be of value to replicate this study across different housing contexts and with different housing organisations in order to examine the role of neighbourhood choice and service provision in more depth.

\section{Acknowledgments}

The authors would like to thank all of the tenants who participated in the study, as well as the staff of the participant organisations who helped out throughout the research. The authors would also like to thank the other members of the project team who contributed to data collection and project governance.

\section{Conflict of Interests}

The authors declare no conflict of interests.

\section{Supplementary Material}

Supplementary material for this article is available online in the format provided by the authors (unedited).

\section{References}

Acevedo-Garcia, D., Osypuk, T. L., Werbel, R. E., Meara, E. R., Cutler, D. M., \& Berkman, L. F. (2004). Does housing mobility policy improve health? Housing Policy Debate, 15(1), 49-98.

Anderson, I., \& Barclay, A. (2003). Housing and health. In A. Watterson (Ed.), Public health in practice (pp. 158-183). London: Palgrave.

Braubach, M., \& Fairburn, J. (2010). Social inequities in environmental risks associated with housing and residential location: A review of evidence. European Journal of Public Health, 20(1), 36-42.

Braubach, M., Jacobs, D. E., \& Ormandy, D. (2011). Environmental burden of disease associated with inadequate housing. Copenhagen: WHO Europe.

Braun, V., \& Clarke, V. (2006). Using thematic analysis in psychology. Qualitative Research in Psychology, 3(2), 77-101.

Cockerham, W. C., Hamby, B. W., \& Oates, G. R. (2017). The social determinants of chronic disease. American Journal of Preventive Medicine, 52(1, Suppl. 1), 5-12.

Cummins, R., \& Kim, Y. (2015). The use and abuse of 'community' and 'neighbourhood' within disability research: An exposé, clarification, and recommenda- tion. International Journal of Developmental Disabilities, 61(2), 68-75.

Flores, E. C., Fuhr, D. C., Bayer, A. M., Lescano, A. G., Thorogood, N., \& Simms, V. (2018). Mental health impact of social capital interventions: A systematic review. Social Psychiatry and Psychiatric Epidemiology, 53(2), 107-119.

Gibson, M., Petticrew, M., Bambra, C., Sowden, A. J., Wright, K. E., \& Whitehead, M. (2011). Housing and health inequalities: A synthesis of systematic reviews of interventions aimed at different pathways linking housing and health. Health and Place, 17(1), 175-184.

Glasgow Centre for Population Health. (2020). Understanding Glasgow: The Glasgow indicators project. Understanding Glasgow. Retrieved from https:// www.understandingglasgow.com

Gunasekara, F. I., Carter, K., \& Blakely, T. (2012). Comparing self-rated health and self-assessed change in health in a longitudinal survey: Which is more valid? Social Science \& Medicine, 74(7), 1117-1124.

Helliwell, J., \& Putnam, R. (2004). The social context of wellbeing. Philosophical Transactions of the Royal Society of London B: Biological Sciences, 359(1449), 1435-1446.

Idler, E. L., \& Benyamini, Y. (1997). Self-rated health and mortality: A review of twenty-seven community studies. Journal of Health and Social Behavior, 38(1), 21-37.

Karsten, L. (2007). Housing as a way of life: Towards an understanding of middle-class families' preference for an urban residential location. Housing Studies, 22(1), 83-98.

Kawachi, I., \& Berkman, L. (2001). Social ties and mental health. Journal of Urban Health, 78(3), 458-467.

Kawachi, I., Subramanian, S., \& Kim, D. (Eds.). (2008). Social capital and health. New York, NY: Springer.

Lochner, K. A., Kawachi, I., Brennan, R. T., \& Buka, S. L. (2003). Social capital and neighborhood mortality rates in Chicago. Social Science \& Medicine, 56(8), 1797-1805.

OECD. (2001). The wellbeing of nations: The role of human and social capital. Paris: OECD.

Pickett, K. E., \& Pearl, M. (2001). Multilevel analyses of neighbourhood socioeconomic context and health outcomes: A critical review. Journal of Epidemiology and Community Health, 55(2), 111-122.

Poder, T. G. (2011). What is really social capital? A critical review. The American Sociologist, 42(4). https:// doi.org/10.1007/s12108-011-9136-z

Portes, A. (1998). Social capital: Its origins and applications in modern sociology. Annual Review of Sociology, 24, 1-24.

Putnam, R. (2000). Bowling alone: The collapse and revival of American community. New York, NY: Simon \& Schuster.

Ritchie, J., \& Spencer, L. (1994). Qualitative data analysis for applied policy research. In A. Bryman \& R. 
Burgess (Eds.), Analyzing qualitative data. London: Routledge.

Schuller, T. (2007). Reflections on the use of social capital. Review of Social Economy, 65(1), 11-28.

Scottish Government. (2011). Social housing allocations: A practice guide. Edinburgh: Scottish Government.

Scottish Government. (2019). Social housing allocations in Scotland: Practice guide. Edinburgh: Scottish Government.

Sellström, E., \& Bremberg, S. (2006). The significance of neighbourhood context to child and adolescent health and well-being: A systematic review of multilevel studies. Scandinavian Journal of Public Health, 34(5), 544-554.

Steptoe, A., Deaton, A., \& Stone, A. A. (2015). Subjective wellbeing, health, and ageing. Lancet, 385(9968), 640-648.

Subramanian, S. V., Lochner, K. A., \& Kawachi, I. (2003). Neighborhood differences in social capital: A compositional artifact or a contextual construct? Health \& Place, 9(1), 33-44.

Szreter, S., \& Woolcock, M. (2004). Health by association? Social capital, social theory, and the political economy of public health. International Journal of Epidemiology, 33, 650-667.

Thomson, H., Thomas, S., Sellstrom, E., \& Petticrew, M. (2013). Housing improvements for health and associated socio-economic outcomes. Cochrane Li- brary. Retrieved from https://www.cochranelibrary. com/cdsr/doi/10.1002/14651858.CD008657.pub2/ abstract

Topp, C. W., Ostergaard, S. D., Sondergaard, S., \& Bech, P. (2015). The WHO-5 well-being index: A systematic review of the literature. Psychother Psychosom, 84(3), 167-176.

Uphoff, E. P., Pickett, K. E., Cabieses, B., Small, N., \& Wright, J. (2013). A systematic review of the relationships between social capital and socioeconomic inequalities in health: A contribution to understanding the psychosocial pathway of health inequalities. International Journal for Equity in Health, 12, 54.

Veenstra, G. (2000). Social capital, SES and health: An individual-level analysis. Social Science \& Medicine, 50(5), 619-629.

Vyncke, V., de Clercq, B., Stevens, V., Costongs, C., Barbareschi, G., Jónsson, S. H., . . Maes, L. (2013). Does neighbourhood social capital aid in levelling the social gradient in the health and well-being of children and adolescents? A literature review. BMC Public Health, 13. https://doi.org/10.1186/1471-2458-1365

World Health Organization Europe. (2007). Large analysis and review of European housing and health status (LARES: Preliminary overview). Copenhagen: WHO Europe.

\section{About the Authors}
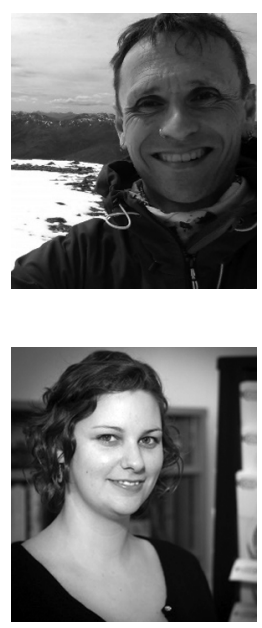

Steve Rolfe $(\mathrm{PhD})$ is a Research Fellow at the University of Stirling. His research uses mixed methods to explore housing outcomes for vulnerable households, and the role of organisations in providing housing and supporting tenants. He has prior research experience in community participation policy and practice, as well as 15 years professional experience in local government.

Lisa Garnham (PhD) is a Public Health Researcher at Glasgow Centre for Population Health. Her background is in health geography, with a focus on social inequality and, especially, the ways in which the spaces we live and work in can create and maintain health inequalities. She has expertise in creative and participatory research methods and is interested in the ways in which research can empower those who engage with it. 